\title{
TOWARDS A NATIONAL PRINT REPOSITORY FOR AUSTRALIA: WHERE FROM AND WHERE TO?
}

\section{Paul Genoni}

In recent years there has been growing international interest in the development of shared facilities to house legacy print collections as a means of providing cost-effective and secure storage. These 'repositories' have in some cases been successfully implemented on a national scale. This article traces the recent history of Australian attempts to reach a similar national solution to the space problems that afflict many of our research libraries. It argues that, although these negotiations have not been successful to date, the opportunity still exists to re-open discussion. It also makes suggestions regarding the organisational structures that are needed to bring about a successful outcome.

AARL June 2007 vol 38 no2 pp84-98.

Paul Genoni, Department of Media and Information, Curtin University of Technology, GPO Box U 1987, Perth, WA 6845. E-mail: P.Genoni@curtin.edu.au

7 he issue of finding adequate long-term storage for print collections has troubled libraries for many years. For most libraries it is the case that their collections continue to grow and, therefore, constantly require additional storage space. The resulting problem has been particularly acute for research libraries, which are often committed to long-term retention of collections, irrespective of immediate usage. Research libraries have typically dealt with the problem on a piecemeal basis. This might have involved strategies such as high-density on-site storage (for example, compactus shelving), or remote storage sites for low-use material. Many of these solutions involved tradeoffs in terms of accessibility and good conservation and preservation practice, but they were necessary in order to cope with expanding collections.

There has been some small respite in recent years with the uptake of digital content, which has noticeably alleviated the need to find storage for rapidly growing periodical collections. There has continued to be growing pressure, however, on storage space for other reasons. In particular, the increased demand 
for new multifaceted collaborative learning spaces in educational institutions has required many libraries to surrender space that was previously available for storage.

The storage problem, therefore, has hardly diminished. Indeed, for many institutions it has been exacerbated in that universities are probably now more reluctant than previously to fund library expansion as a means of dealing with the issue. Many universities face chronic shortages of land for new buildings, and there is evidence of a belief that the impact of digitisation should result in a reduced need for additional storage space. There has also emerged a possible solution to this lack of storage space, one that has been attracting increasing international interest and which has been adopted to some extent in Australia - the repository.

\section{REPOSITORIES DEFINED}

What exactly is a repository? The terminology in this regard is far from clear, with the terms 'repository' and 'store' often being used interchangeably. For the purposes of this paper, however, it is desirable and possible to distinguish between them in a way that appears to be consistent with emerging usage. In this context a repository is defined as:

a means through which multiple institutions work together and pool resources to manage significant portions of their holdings. They offer a shared space in which collections deposited by different libraries are maintained under a common regime: they are included in a common inventory-control system, subjected to common standards for bar codes and labelling, and shelved in standardized units. Their circulation is managed by a single organization. ${ }^{1}$

Repositories are, therefore, a joint library storage facility, the operation of which is supported by unified management policies and systems. The multi-institutional and unified management and operational aspects of a repository provide it with its particular status, are crucial to delivering its benefits, and distinguish it from a 'store'. Notably in this regard, a print repository has a different connotation from a digital repository, with the latter often being characterised by an association with a specific institution.

A repository should also be distinguished from a 'depository', a term applied to those services that receive material as the result of legislative obligation. In Australian terms this would cover some aspects of the collections of the National Library of Australia and the state libraries, which receive material under the legal deposit provisions of copyright legislation.

The reasons why repositories have emerged as an appealing response to the storage of print materials have been described elsewhere and need not be repeated here in detail. ${ }^{2}$ In summary, however, the principle advantages are threefold. First, individual libraries and institutions are relieved of the high direct cost of 
storing and maintaining items that receive little or no use, and can forestall the significant capital expenditure required to house growing collections. Second, the library system or network served by the repository benefits, as it ensures the permanent preservation and availability of low-use materials in secure and cost-effective storage. Third, the research community served by the repository benefits from the efficiencies in discovery, retrieval and delivery that are possible in a repository environment, which can support a technological and service infrastructure that could not be justified for a single library operating a local store.

Underlying the emerging importance of repositories is the awareness that 'traditional' library storage for print material is an inefficient and expensive means of handling low-use material, and is becoming unsustainable in an environment that increasingly favours the efficiencies resulting from collaboration at the system level.

\section{NATIONAL REPOSITORIES}

In particular, recent developments in delivery technologies have made it feasible to conceptualise repositories that serve wide geographic areas. As a result, the concept of the national repository has emerged and gained favour. National repositories of research materials were established as early as the late 1980s in Finland $^{3}$ and Norway and the 1990s in France. ${ }^{5}$

The European interest in national repositories has also been evidenced by recent developments in the UK. Scotland implemented a national academic library store - the Collaborative Academic Store for Scotland (CASS) - in 2004. ${ }^{6}$ CASS was developed as a joint initiative of the Scottish Confederation of University and Research Libraries and the National Library of Scotland. This joint activity between academic libraries and a national library has been mirrored in England, where the lead in repository development has been taken initially by the Higher Education/British Library Task Force reporting to the Research Support Libraries Programme, and subsequently the Consortium of Research Libraries in the British Isles (CURL) working in conjunction with the British Library and the Research Information Network (RIN).

A key outcome of the UK activity has been the completion of the 2005 report Optimising Storage and Access in UK Research Libraries. This report offered several alternatives for the development of a national repository for research materials, and following a period of consultation during 2005 and 2006 a consensus has emerged for Option 4, which is based around a repository system - the UK Research Reserve (UKRR) - based on the lending collection of the British Library.

In the US, practical evidence of growing support for repositories has been provided by the development by collaborating university libraries of a number of shared regional facilities. ${ }^{9}$ There is, as yet, no nationally coordinated approach to the development of regional repositories, but there is evidence of increasing interest in the concept. This interest was apparent in 2001 when the Task Force 
on the Artifact in Library Collections issued its final report to the Council of Library and Information Resources (CLIR), recommending the development of a network of 'regional repositories'. The Task Force report called upon librarians and researchers to act collaboratively and

advocate for the development of regional repositories of artifactual collections that reduce duplication of effort, create economies of scale, and ensure that the greatest number of unique or scarce priority items are preserved and made accessible to researchers. ${ }^{10}$

Building on this report, CLIR commissioned a second report, Developing Print Repositories, which provided a more detailed analysis of the issues involved in developing regional repositories and the prospects for implementing a national network. This report concluded that

With the appropriate resources in place, one could imagine the major North American research libraries, regional repositories, and national-level repositories linked in a network that enables strategic management of the important primary resources for scholarship. ${ }^{11}$

\section{CURRENT AUSTRALIAN REPOSITORIES AND STORES}

Australia currently has three major facilities for storing print research materials. It should be noted that they may not meet all of the conditions described in the definition given above, particularly with regard to fully integrated policy and stock-control regimes; but they do meet the basic requirements in that they are multi-institutional and have a component of unified management.

The first significant Australian repository was the Joint Library Store developed by Flinders University and the University of Adelaide and constructed in 1984. The initial store housed some 500000 volumes; this capacity was doubled by an extension completed in 1997. The consortium of universities managing the store has since expanded to include the University of South Australia and the facility now goes by the name of the Universities' Research Repository South Australia. It has been claimed that the facility

has a track record of providing cost effective and efficient service to its partner libraries and their users. It is an economic, secure, low technology facility, that has proven to be very successful in the preservation and delivery of information and in alleviating pressure on prime library accommodation. ${ }^{12}$

Perhaps the most high-profile Australian repository is the CARM Centre managed by CAVAL Collaborative Solutions. CARM, located in the Melbourne suburb of Bundoora on land owned by La Trobe University, has operated since 1997. It provides services to member libraries, which currently consist of academic libraries from Victoria, plus the University of New South Wales. CARM has a capacity of approximately one million volumes, with planning underway for the 
development of CARM 2, which will double the current capacity. It should be noted that CARM has aspects of a genuine repository, with the ownership of material ceded to CARM by the depositing library. It also has aspects of a store, in that it is used by some libraries to provide temporary storage for material for which they retain ownership. Nevertheless, CARM has been acknowledged internationally as a model of good governance for developments of this type. A major US report described CARM as 'the most fully realized model of a cooperatively funded interinstitutional repository', ${ }^{13}$, and according to CHEMS Consulting in the UK it is 'one of the most successful collaborative stores.'

The third Australian facility of note is a recently developed store that brings together holdings of the State Library of Victoria and Ballarat University, and is located at the University's Mt Helen Campus, ten kilometres from Ballarat in regional Victoria. The store, opened in late 2005, has a capacity in excess of one million volumes.

\section{WHERE FROM?}

Against the background of these international and Australian developments has been the long running consideration given to developing a national repository for Australia. For the most part this has been driven from within the Council of Australian University Librarians (CAUL); it has been running since at least 1998. The first significant proposal flowing from these discussions was a report prepared by CAVAL in 1999 for the development of a repository to be called the Australian and New Zealand Research Information Centre. As the name indicates, this was a proposal for a trans-Tasman repository forming 'a single copy research collection of monographs and serials'. The proposal was for a distributed repository, to be housed in sites in Australia and New Zealand, and incorporating the existing CARM Centre and South Australian collections. The business plan was based on a funding model underwritten by savings in storage costs, with an estimate that storage per volume 'will be 7 to $10 \%$ of the cost of storage in a library. ${ }^{16}$ This report informed discussions at a National Cooperative Store Workshop convened by CAUL in August 1999. Also in attendance were representatives of the National Library, the state libraries of Victoria and South Australia, and the CSIRO. A decision was taken by this meeting to fund the further development of a business plan and funding model for 'a national cooperative digital and archive store linking regional sites under a common management and technical structure ${ }^{17}$, and the National Cooperative Store Working Party was created for the purpose.

By March 2000 CAUL had been presented with a report from the Working Party recommending the creation of a body, to be called Research Resources Australia (RRA), which would have the role of 'focus(ing) on national issues regarding storage' and the aim 'to create a national cooperative network that facilitates access and delivery of research materials from repositories across Australia. In effect a national consortium. ${ }^{18}$ Despite the clarity of this aim, some of the details of the proposal indicated a degree of tension between the concept of a national repository and the role of the existing regionally-based Victorian 
and South Australian repositories. The initial proposal recommended that the RRA executive committee would consist of a board of four members to be drawn from the management of the Victorian and South Australian repositories, with separate tasks allocated to RRA and the 'existing state bodies'. At the same time other state initiatives were also being undertaken, such as the Western Australian Group of University Librarians (WAGUL) proposal for the creation of a regional store as part of the implementation of a Western Australian Knowledge Centre. ${ }^{19}$ The WAGUL proposal included the usual rationale for store development, noting that 'capital costs of building extensions are prohibitive' as well as the need to 'reduce the unit cost of storage.'.

The National Cooperative Store Working Party continued to work towards finalising the RRA business plan and the issue remained as part of the business of subsequent CAUL meetings. By early 2001 the Working Party had drafted a Memorandum of Understanding that provided a framework for the future operations of RRA. The Memorandum of Understanding (signed in May 2001 by representatives of CARM and the South Australian store) described the role of RRA as being, inter alia, to:

- create and promote a national collaborative network to provide cost-effective storage and retrieval of research materials; and

- develop the mechanisms to enable researchers to readily identify the resources located in the repositories.

The Memorandum of Understanding also declared that RRA would 'focus on the national role of the repositories (while) existing state bodies will continue their role in determining policies and procedures' related to the management of the network of regional repositories. ${ }^{21}$ Despite this progress the March 2001 GAUL meeting recorded 'disappointment that the process was so slow, and that the operation wasn't close enough to CAUL. ${ }^{22}$ This latter comment points to one of the problems that may have afflicted the RRA proposal - the narrow base of decision-making represented on RRA, which apparently left some CAUL members (let alone representatives of other library sectors) believing that they had little input into the process.

The issue next came before CAUL in a substantial way at their meeting in April 2002. By this time there had been two important developments. First, RRA had prepared a set of principles which gave a clearer vision of the future operation of the repository. These principles envisaged a repository which:

- included last copies and unique copies;

- included both journals and monographs;

- had a minimum of $50 \%$ of funding from external sources;

- required depositing libraries to pay the costs associated with depositing; and

- required a very high level of CAUL participation.

Second, two applications for funding from the Department of Education, Science and Training (DEST) of approximately $\$ 8$ million to support the further development of the project had been rejected. The records of the April 2002 
CAUL meeting reveal that, although there was general support for continued work towards a cooperative national store, a number of members held reservations. Some of these reservations included:

- the governance model, including the legal status of RRA;

- an operational structure based on the existing regional stores, rather than a genuinely national framework;

- costs, including both the general operating costs and the cost incurred by depositing libraries; and

- categories of material which may or may not be included. ${ }^{23}$

The meeting agreed that CAUL should 'continue working towards the development of a business case, together with an outline of the proposed governance model', with a view to preparing another funding application to DEST, 'even if not all members were able to support it at this time'.

Consideration of the matter continued within CAUL throughout 2002 and 2003, including the preparation of a further report by an independent consultant on matters relating to finance and governance. CAUL also held discussions with the National Library of Australia (NLA) and the State Library of Victoria, and was represented at meetings of the Council of Australian State Libraries (CASL, now National and State Libraries Australasia (NSLA)) to further promote the concept.

A final report, National Collaborative Library Storage Strategy, was prepared prior to the CAUL meeting of April 2004. ${ }^{25}$ This report gave a pessimistic account of the prospects for a national repository, noting the divisions on the issue within CAUL and linking this lack of consensus to the lukewarm response from DEST. The report also noted the preference by DEST to support projects aligned with e-research infrastructure. There was, at least, continued public support from within DEST for a print repository at this time. The final report issued by DEST's Information Infrastructure Advisory Committee (IIAC) in November 2002 nominated 'collaborative storage facilities for research publications' as an initiative for future funding and notionally allocated $\$ 4-5$ million to 'provide a national facility for the storage of research material which is little used'. ${ }^{26}$ The Higher Education Information Infrastructure Advisory Committee, which reported to DEST in May 2003 on a funding mechanism to replace the IIAC, recommended that a working party be established 'to develop a specification for the provision of storage facilities which meet agreed protocols' and provided a detailed list of the protocols that would need to be considered. ${ }^{27}$

The National Collaborative Library Storage Strategy report concluded by presenting CAUL with three scenarios for decision. These ranged from continued lobbying for the implementation of the national repository based on at least $80 \%$ support from Australian Vice-Chancellors' Committee (AVCG) institutions, to abandoning the concept altogether. At the CAUL meeting that considered the report it was minuted that 'all agreed to drop the proposal ${ }^{28}$, thereby effectively bringing to an end to RRA and the concept of a national repository. 
The higher education bodies such as CAUL and IIAC were not the only committees in a position to consider national or regional solutions to storage problems during this period. The NLA led some discussion of storage through the Australian Library Collections Taskforce (ALCT), whose membership consisted of representatives of Australian academic and research libraries and research institutions. Matters relating to cooperation infrastructure and intersectoral library cooperation fell within the ALCT terms of reference ('The Task Force will identify and recommend strategies that will facilitate improved access to library materials'), although the specific issue of a repository was largely dealt with through reporting from committee members regarding the RRA developments. The ALCT was, however, discontinued in 2003, and no body with similar responsibilities has since emerged under the auspices of the NLA.

The issue of repositories has been raised at meetings of the Peak Bodies Forum, an NLA-sponsored group consisting of representatives of the peak professional bodies within the library sector, which first met in February 2002. The issue of 'cooperative storage options' was discussed at that initial meeting. It was noted that, although developments to that point had been led by the university sector, 'there is a need for cooperative stores which cater to other sectors, such as special libraries, parliamentary libraries and other government libraries'. ${ }^{29}$ The issue has not, however, featured at subsequent meetings of the Forum. Matters relating to information infrastructure have also been of concern to the National Scholarly Communications Forum, a body sponsored by the Australian learned academies and including representation from CAUL, CASL/NSLA and the NLA. In a series of round tables conducted since 1994 the Forum has addressed issues relating to cooperative library services, including the Distributed National Collection, the future of the book, and the evolution of scholarly publishing. ${ }^{30}$

\section{WHERE TO?}

Despite the eventual demise of the RRA proposal, interest in a national repository has persisted. This ongoing interest is evidenced from within CAUL where the issue of storage has continued to be raised at meetings - on several occasions in the context of joint storage for JSTOR titles, and, most recently, in September 2006 when Alan Smith of the State Library of South Australia (attending with other members of NSLA) led a review of developments since the 1999 Workshop. The state-based groupings of CAUL libraries have also continued to discuss the possibility of developing regional repositories outside Victoria and South Australia. The June 2003 meeting of the University Librarians in the State of New South Wales (UNISON) noted 'that a regional store for NSW will need to be arranged within the next few years. ${ }^{31}$ In the absence of development of such a store the University of New South Wales joined CAVAL in 2005 so that it could use the storage service provided by the CARM Centre. The Queensland University Libraries Office of Cooperation (QULOC) also discussed a 'cooperative storage proposal' in $2006^{32}$, with member libraries expressing concern about space shortages in their existing libraries and storage facilities. 
It is apparent, therefore, that the need for additional storage is unabated, and that libraries are seeking collaborative solutions where possible. In the absence of any sustained push for a national response, however, the danger lies in a series of local and regional responses that will result in fragmented, under-funded and probably temporary outcomes. Certainly, if such solutions are implemented, they will lack the policy or technology infrastructures necessary to optimise the benefits of cooperative storage and achievable only within a coordinated national system.

\section{A UNIFIED POLICY FRAMEWORK}

The importance of a unified policy framework is critical. The potential benefits of a national print repository will only be fully realised if there is agreement by participants on a number of key issues that have an impact on the management systems and technologies that can be put in place for discovery and delivery of items, and on the confidence with which libraries can commit items to store or discard them from their collections.

Based on previous experience, it appears that there will be two major areas for policy negotiation. The first of these is the relationship between the existing repositories and a new national service. A national repository does not necessarily imply a single physical storage site, although this might be the ideal solution if an Australian repository were to be designed as a 'green field' proposition. It is, however, necessary to deal with the practicalities of the existing repositories. This means that a national print repository will in all likelihood incorporate the existing repository infrastructure, plus the storage facilities of the NLA and state libraries. This might require a top down strategy, requiring the imposition of a national facility that incorporates and normalises the existing repositories. Alternatively, it might function by expanding the roles of the existing repositories so that they become, de facto, a national service. It was a weakness of the RRA proposal that this issue was not fully resolved and it is likely to require careful management in a revamped proposal.

Second, there is likely to be some negotiation required regarding ownership policy. The cost-effectiveness of a repository is optimised if contributing libraries cede ownership. This is necessary for achieving maximum storage density, eliminating duplication within the repository, and allowing libraries to deduplicate with confidence. This situation has not been achieved with the existing Australian repositories; even the CARM Centre holds significant amounts of materials that are still owned by member libraries. Ideally, a repository is built on a single collection, the ownership of which is shared by members, and which is intended to be maintained in perpetuity. The alternative is a series of stores, where material is simply placed pending some likely future decision to discard. A policy of ceded ownership will require a substantial change of culture for libraries who feel there is competitive advantage in maximising their collection size. 


\section{CHANGES IN THE AUSTRALIAN INFRASTRUCTURE ENVIRONMENT}

If a national repository remains the best outcome for Australian research interests, is there any reason to be optimistic that a move in this direction will be more successful at this time?

First, it can be argued that the imperatives for change are now clearer. In part this is as a result of the increasing space shortages faced by libraries as they struggle to integrate new uses, coupled with the growing realisation that funding for expanded local storage is going to be increasingly difficult to obtain. Second, the very detailed examination and resolution in favour of a national repository solution in the UK adds weight to the principles of collaboration and mutual benefit on which a repository must be based. This is not to argue that the UK model - with a repository based on the existing collection of the national library - would be viable in Australia, but the process of evidence-gathering and consultation undertaken in the UK should convince Australian research libraries of the value of a national repository. As noted, one of the problems troubling the previous application for DEST funding was the lack of unanimity amongst the CAUL membership; it may now be possible to get wider agreement on the need for a national repository.

Australia also has different mechanisms for policy development in the higher education and collections sectors than was the case several years ago, and these may provide new sources of support for funding applications. The first of these is the Australian Research Information Infrastructure Committee (ARIIC), which reports to DEST as the successor to the IIAC. ARIIC was established in late 2003 with the role of advising government on the information infrastructure requirements of the higher education sector. ARIIC's support would be critical to the success of any future applications for DEST funding. The Committee's current membership includes representatives of the NLA and CAUL, together with representatives of DEST, the Australian Research Council, and the AVCC. To date ARIIC's activities have been confined almost exclusively to digital infrastructure, but it is a potentially influential avenue in convincing DEST of the value of a national repository for legacy print materials.

A second recently created avenue of potential support is the Collections Council of Australia (CCA), established in 2004 by federal, state and territory governments. The responsibility of the Council includes heritage collections from all sectors (libraries, museums, galleries and archives), with a stated goal 'to develop capacity and efficiencies within the collections sector. ${ }^{33}$ Libraries are represented ex officio on the CGA Board of Directors through the Chair of NSLA. The CCA is still in the process of establishing its role. With its diffuse activity across the various collecting sectors it may have limited capacity to support a focussed initiative such as a national repository. 


\section{LEARNING FROM THE UK}

What seems to be apparent, however, is that any future applications for funding would benefit by broadening the basis of agreement to include more than just the higher education sector. A key to the progress made with the implementation of national stores in Scotland, and more recently in the wider UK, has been the strong alliances formed between the libraries of the higher education sector, national libraries, and other research libraries and bodies. The impetus towards the UK print repository was driven by the Higher Education/British Library Task Force (formed in 1999), which commissioned an initial report on the issue ${ }^{34}$, and by the Research Support Libraries Group, formed by UK higher education funding bodies to support the provision of research information through university libraries.

Following the work of these groups, the carriage of the UK national repository has continued to be managed by broadly representative bodies. Leading the project is CURL, whose membership includes more than 20 of the leading UK university libraries, the national libraries of England, Scotland and Wales, and several other research libraries with collections of national significance. It was CURL and the British Library who commissioned the report Optimising Storage and Access in UK Research Libraries. GURL has subsequently constituted a Task Force and Advisory Group with express responsibility for implementing the UKRR based on funding received in 2006.

The other major UK player working in conjunction with GURL is the RIN, formed in 2005 by a consortium of UK sponsors, consisting of the four higher education funding bodies, the three national libraries, and eight research councils. The RIN's mission is 'to lead and co-ordinate new developments in the collaborative provision of research information for the benefit of researchers in the UK'. ${ }^{35}$ The RIN has a broad-ranging and ambitious agenda to lead, develop, coordinate and advocate for research information. One of the six specific aims given in their strategic plan is: 'to lead the development of a programme to sustain and enhance management and development of the aggregate UK collection of published hard copy resources'. ${ }^{36}$

It is relevant to the Australian situation that the RIN was established following the final report of the Research Support Libraries Group, which found that 'existing providers of research information work in loosely coordinated networks which lack the unified and focussed strategic leadership required to pull together a national framework of interdependent functions and to generate comprehensive and sustainable solutions to the information needs of researchers'. ${ }^{37}$ It can be argued that this finding also describes the situation in Australia.

Australia currently lacks a body with broad participation and breadth of responsibilities comparable to those of GURL or the RIN. It is desirable that any move to reopen discussion on a national print repository involve, in the first instance, the formation of a body similar to GURL, which represents the broad range of research libraries. Australian research interests receive essential support not only from the CAUL libraries, but also from the collections of the National, state, government and other special libraries. Research libraries generally, 
and the communities they serve, would benefit from a forum that brought together those libraries with a significant role to play in providing library-based research infrastructure, including a possible national repository. It is the case that the NLA has a history of partnering with CAUL in developing proposals for infrastructure funding. The recent example of the State Library of Victoria and the University of Ballarat implementing a joint storage facility demonstrates continued collaboration between the CAUL and NSLA sectors.

There might also be a need for a second body, with a remit similar to that of the RIN, which might even have the single purpose of achieving a national repository. This could be a body that works closely with the research library grouping described above and draws its representation from a range of organisations, both library and non-library based, which share a stake in research infrastructure. These might include, for example, CAUL, NSLA, CSIRO, Government Libraries Information Network, Universities Australia (formerly the AVCG), the ARC, the learned academies, the Collections Council of Australia, and the existing repositories. Such a body could assume responsibility for resolving the key management and policy issues associated with a national repository, and could undertake lobbying and advocacy prior to an application for DEST research infrastructure funding.

\section{CONCLUSION}

There are many reasons to believe that Australian research libraries and communities would benefit substantially from a national print repository. It will only be possible, however, with the right structure for leadership, coordination and advocacy. There is much that can be learnt from the UK experience in this regard. Australian library leaders should look to building a strong base of crosssectoral support for a renewed bid.

Australian librarianship has an enviable record of cooperation in building critical technical and service infrastructure. Initiatives such as Libraries Australia have been made possible by coordinated cross-sectoral activity, undertaken in the service of Australian research communities. What has been less successful is the use of this infrastructure to underpin further collaboration with regard to the long-term development and maintenance of collections. The prospect of a national repository provides a further opportunity to achieve such an outcome. While a body or committee with representation from various library sectors and other relevant parties may add complexity to the task of achieving consensus on matters relating to management and policy, it appears that it will be necessary for securing a national print repository for Australia.

\section{Acknowledgements}

This is a revised version of a paper delivered to the seminar, Wagging the Long Tail: Managing Print Collections in a Digital Age, sponsored by CAVAL Collaborative Solutions and held in Melbourne on 3 May 2007. I would like to thank Margaret Jones and Helen Hayes for their comments on an earlier version of the paper. 


\section{NOTES}

1. B F Reilly Developing Print Repositories: Models for Shared Preservation and Access Council on Library and Information Resources Washington 2003 p2 at http://www.clir.org/pubs/reports/pub117/pub117.pdf

2. See for example CHEMS Consulting Optimising Storage and Access in UK Research Libraries: A Study for CURL and the British Library 2005 at http://www.curl.ac.uk/about/documents/CURL_BLStorageReportFinalendSept2005.pdf; L Dempsey 'Libraries and the Long Tail: Some Thoughts about Libraries in a Network Age' D-Lib Magazine 2006 vol 12 no 4; S O'Connor 'Collaborative Strategies for Low-use Research Materials' Library Collections, Acquisitions \& Technical Services 2004 vol 28 pp5157; S O'Connor A Wells \& M Collier A Study of Collaborative Storage of Library Resources: Report for the Higher Education/ British Library Task Force CAVAL Collaborative Solutions 2001; Reilly op cit; Task Force on the Artifact in Library Collections The Evidence in Hand: Report of the Task Force on the Artifact in Library Collections Council on Library and Information Resources Washington 2001 at http://www.clir.org/pubs/ reports/pub103/contents.html

3. P Vattulainen 'National Repository Initiatives in Europe' Library Collections, Acquisitions, \& Technical Services 2004 vol 28 pp39-50; J Saarti 'From Printed World to a Digital Environment: The Role of Repository Libraries in a Changing Environment' Library Management 2005 vol 26 no 1/2 pp26-31.

4. J Henden 'The Norwegian Repository Library' Library Management 2005 vol 26 no $1 / 2$ pp73-78

5. Vattulainen op cit.

6. C M Nicholson 'CASS: A Collaborative Academic Store for Scotland' Library Management 2005 vol 26 no 1/2 pp32-41.

7. CHEMS Consulting op cit.

8. 'Evolution or Revolution: Debating the Future of the UK's Higher Education Information Infrastructure: A Conference' New Review of Academic Librarianship 2005 vol 11 no 2 pp 153-176.

9. L Payne 'Depositories and Repositories: Changing Models of Library Storage in the USA' Library Management 2005 vol 26 no 1/2 pp 10-17.

10. Task Force on the Artifact in Library Collections op cit.

11. Reilly op cit $\mathrm{p} 40$.

12. K L Baudinette 'The Flinders University and University of Adelaide Joint Library Store' at http://www.caul.edu.au/caul-doc/store-choate.doc

13. Reilly op cit p32.

14. CHEMS Consulting op cit p24.

15. CAVAL Ltd The Case for a National Information Research Centre: Toward a Business Plan 1999 p3 at http://www.caul.edu.au/caul-doc/store-caval.doc

16. CAVAL Ltd op cit $\mathrm{p} 3$. 
17. Council of Australian University Librarians A National Cooperative Store Network: Workshop Convened by CAUL: Flinders University, Adelaide, 6 August 19991999 at http://www.caul.edu.au/meetings/Store990806.min. doc

18. H Livingston National Cooperative Store: Memorandum to CAVAL Board/ CARM Committee, February 112000 at http://www.caul.edu.au/caul-doc/ store-RRA.doc

19. Western Australian Group of University Librarians Western Australian Knowledge Centre: A Conceptual Framework for Future Western Australian Regional Cooperative Development 1999 at http://www.caul.edu.au/cauldoc/store-wagul.doc

20. Western Australian Group of University Librarians op cit p7.

21. Council of Australian University Librarians CAUL Strategic Plan, Report to CAUL, 20 February 2001 at http://www.caul.edu.au/caul-doc/RRA20011. doc

22. Council of Australian University Librarians CAUL Minutes, March 2001 at http://www.caul.edu.au/meetings/caul20011.min

23. Council of Australian University Librarians CAUL Minutes, April 2002 Appendix I at http://www.caul.edu.au/meetings/caul20021 min.doc\#app 1

24. Council of Australian University Librarians CAUL Minutes, April 2002 Appendix I op cit.

25. Council of Australian University Librarians National Collaborative Library Storage Strategy 2004 at http://www.caul.edu.au/caul-doc/caul20041store. doc

26. Department of Education, Science and Training Information Infrastructure Advisory Committee Research Information Infrastructure Framework for Australian Higher Education 2002 p51 at http://www.dest.gov.au/NR/ rdonlyres/464431A2-6C45-48F9-B9A1-80FD09856FBA/898/report.pdf

27. Department of Education, Science and Training Higher Education Information Infrastructure Implementation Steering Committee Report of the Higher Education Information Infrastructure Implementation Steering Committee 2003 p13 at http://www.dest.gov.au/NR/rdonlyres/64E24496176A-45A5-9542-3FE1AFCGB79B/899/report.pdf

28. Council of Australian University Librarians CAUL Minutes, April 2004 at http://www.caul.edu.au/meetings/caul20041min.doc

29. National Library of Australia Peak Bodies Forum Minutes, Friday February 15, 2002 at http://www.nla.gov.au/initiatives/meetings/peakbod/min 150202. html

30. The Australian Academy of the Humanities National Scholarly Communications Forum at http://www.humanities.org.au/Events/NSCF/ Overview.htm

31. University Librarians in the State of New South Wales Minutes of the UNISON Committee meeting, 2nd June, 2003 at http://www.unison.nsw. edu.au/__data/assets/word_doc/214/02June03.doc 
32. Queensland University Libraries Office of Cooperation Minutes, 31st March 2006 at http://www.quloc.org.au/

33. Collections Council of Australia The Collections Plan 2006-2009 Collections Council of Australia Ltd 2006 p3 at http://www.collectionscouncil.com.au/ corporate+documents.aspx?DMXModule $=544 \&$ EntryId=469\&Command =Core_Download

34. O'Connor Wells \& Collier op cit.

35. Research Information Network About the Research Information Network at http://www.rin.ac.uk/about

36. Research Information Network Strategic Plan at http://www.rin.ac.uk/ strategic-plan

37. Research Support Libraries Group Final Report Higher Education Funding Council for England 2003 pl at http://www.rslg.ac.uk/final/final.pdf 